\title{
The Impact of Enactive /Vicarious pre-reading Tasks on Reading Comprehension and Self-Efficacy of Iranian Pre-Intermediate EFL Learners
}

\author{
Arezoo Eshghipour (Corresponding author) \\ Department of TEFL, College of Literature and Foreign Languages, Islamic Azad University, Karaj Branch, Alborz, Iran \\ E-mail: arepoor@yahoo.com \\ Gholamhassan Famil Khalili \\ Department of TEFL, College of Literature and Foreign Languages, Islamic Azad University, Karaj Branch, Alborz, Iran \\ E-mail: familkhalili@yahoo.com
}

\author{
Received: 17-05-2015 \\ Accepted: 01-09-2015 \\ Advance Access Published: October 2015 \\ Published: 01-01-2016 \\ doi:10.7575/aiac.ijalel.v.5n.1p.74 \\ URL: http://dx.doi.org/10.7575/aiac.ijalel.v.5n.1p.74
}

\begin{abstract}
This study investigated the effect of enactive pre-reading tasks on Iranian pre-intermediate EFL learners' reading comprehension and self-efficacy. Moreover, it explored whether Iranian per-intermediate EFL learners' reading comprehension and self-efficacy are influenced by vicarious pre-reading tasks. The required data was gathered through a reading comprehension passage entailing 20 comprehension questions and a 30 -item self-efficacy questionnaire with 5 -point Likert-scale response options. A total of 66 participants (including 34 individuals in the enactive group and 32 leaners in the vicarious one) took part in this study. The Pearson formula, an independent T-Test, paired T-test, and the Mann-Whitney $U$ test were used to analyze the data. Based on the findings of the study, enactive pre-reading tasks played a key role in the Iranian pre-intermediate EFL learners' reading comprehension ability. Moreover, it was found that vicarious pre-reading tasks served an important role in the Iranian pre-intermediate EFL learners' self-efficacy.
\end{abstract}

Keywords: Enactive Learning, pre-reading tasks, reading comprehension, self-efficacy, vicarious learning

\section{Introduction}

Painting on caves from tens of thousands of years ago, human beings sought to create permanent records of their findings and feelings. With the passage of time, improvements in written systems require a man to acquire the skill of decoding written symbols. Accordingly, learning to read is a necessity as it provides the reader with one of the most basic requirements for success. Reading, an inseparable and ubiquitous part of any language learning program, is one of the demands of people in everyday life. Comprehension is the main component of reading because gaining different shades of meaning is the ultimate goal of a reading process that enables individuals to communicate with one another through written texts. Stanley (1978) said that encountering authentic materials that are produced by native people, language learners' main problem is to deal with new structures and new vocabularies. Low levels of proficiency in reading are because of poor performance and the lack of ability to use appropriate and purposeful learning strategies. On the other hand, learners are unaware or unconscious of how to use their second language (L2) knowledge or how to gain information as a doer of action or observer. Most of the time, learners are not able to dedicate enough time and effort in order to comprehend the text.

Encountering long and complex passages of reading, students expect the teacher to be responsible for their comprehension. However, his responsibility is to teach learners how to read and comprehend directly or indirectly. Nowadays, in foreign language learning and teaching, traditional reading methods are insufficient because in this way teachers have to be able to provide all kinds of skill and knowledge without paying attention to the learners' expectations. Schunk (2012) explained that "learning occurs either enactively through actual doing or vicariously by observing models perform (e.g. live, symbolic, portrayed, electronically)" (p. 121). In fact, based on the idea of social cognitive theory, learning occurs in a social environment. In particular, vicarious learning includes using sources such as television, video, computer, books, magazine, cartoon character, or even live materials for learning in the field of teaching English as a foreign language (TEFL).

The concept of self-efficacy is raised by Bandura (1986) who defined it as "people's judgments of their capabilities to organize and execute courses of action required to attain designated types of performances" (p. 391). Wong (2005) claimed that in the area of language learning, low self-efficacy and inability to use learning strategies lead to the lack of motivation and performance in tasks and activities; consequently, the result reduces the learners' motivation and capabilities in performing tasks.

Although studies have been conducted on reading comprehension with different kinds of strategies and issues, little attention has been paid to the possible effect of enactive and vicarious learning in the field of TFEL. To the best of 
researchers' knowledge, no study has been conducted to reveal that whether employing enactive learning is of use to language learners' reading comprehension and self-efficacy or it is the use of vicarious learning that enables them to become more competent language learners.

Considering the importance of English as a Foreign Language (EFL) learners' problems in reading comprehension on the one hand and the strong connection between successful comprehension and self-efficacy on the other hand, one way to improve the students' reading comprehension might be the introduction of enactive and vicarious learning. Consequently, this research aims at giving educators new opportunities not only to reflect on their learning and teaching but also to explore how effective and useful the new approaches and methods are. By using enactive and vicarious learning, teachers may be able to engage learners in much practice and enable self-efficacious learners to gain more insight about their capabilities and therefore accept more responsibilities for their learning. In the same vein, this study first explored the impact of enactive learning against vicarious learning on EFL learners' self-efficacy. Secondly, it explored the impact of these two learning processes on the subjects' reading comprehension.

Accordingly, to fulfill the purpose of this study, the following questions were formed:

$\mathrm{Q}_{1}$. Do enactive pre-reading tasks affect Iranian pre-intermediate EFL learners' reading comprehension?

$\mathrm{Q}_{2}$. Do vicarious pre-reading tasks affect Iranian pre-intermediate EFL learners' reading comprehension?

$\mathrm{Q}_{3}$. Do enactive pre-reading tasks affect Iranian pre-intermediate EFL learners' self-efficacy?

Q4. Do vicarious pre-reading tasks affect Iranian pre-intermediate EFL learners' self-efficacy?

In order to investigate the above mentioned research questions empirically, the following null hypotheses were proposed:

$\mathrm{H}_{1}$. Enactive pre-reading tasks do not affect Iranian pre-intermediate EFL learners' reading comprehension.

$\mathrm{HO}_{2}$. Vicarious pre-reading tasks do not affect Iranian pre-intermediate EFL learners' reading comprehension.

$\mathrm{HO}_{3}$. Enactive pre-reading tasks do not affect Iranian pre-intermediate EFL learners' self-efficacy.

$\mathrm{H}_{4}$. Vicarious pre-reading tasks do not affect Iranian pre-intermediate EFL learners' self-efficacy.

\section{Literature review}

\subsection{Reading comprehension}

The ability to read in a second language is considered to be a necessary skill for academic success. Nowadays, teachers attempt to employ more strategies to help readers and encourage them to become effective readers and successful comprehenders. Learning reading strategies is one of the essential factors in gaining success in reading comprehension (Zainol Abidin \& Riswanto, 2012). Block, Gambrell, and Pressley (2002) emphasized that in order to enhance reading comprehension the teacher must teach learners what to do and how to use comprehensive strategies in order to put the pieces of the puzzle together to form the big picture.

As Pardo (2004) stated, for developing readers who are good comprehenders, teachers should teach them decoding skills, enable them to build fluency, build and activate their background knowledge, teach new words, motivate and engage them to respond to texts in personal ways. Modeling, which includes teachers' action and students' observation, is among the paramount techniques of vicarious learning that enables learners to activate prior knowledge and schema (Schunk, 2012).

The main purpose of learning to read is to understand the meaning. Three phases for teaching reading are usually recommended by specialists including pre-reading, while-reading, and post-reading tasks (Chastain, 1988; Hedge, 2008; Mirhassani \& Ghaemi, 2007). During the pre-reading stage, readers are able to do a number of things such as dedicating a lot of time, effort, or attention to the context of the text, realizing or understanding what happens in the content of the text, determining the reason and cause of reading, finding a word to say about the topic, expressing their own experiences that are connected with the topic, trying to activate present cultural knowledge, and getting familiar with the vocabulary of the text. The teacher can provide readers with schematic and language knowledge. At this stage, there are different ranges of activities that the teacher can choose and combine to form this stage. For instance, the teacher can make students discuss and talk about the pictures of the text, look at the title and predict the text, express their ideas about the topic and show their agreement or disagreement, and pose a set of questions and provide their answers. Pre-reading activities are also supposed to increase readers' interest in the topic and enable them to express their attitudes toward the text. In the pre-reading stage there is an opportunity for the teacher and learners not only to practice some key components of language but also to activate readers' prior knowledge of the topic (Hedge, 2008). Predicting what will happen is considered to be a star player in comprehending the text. According to Tompkins (2007), learners must talk about what they know about the topic or the type of the text. Roe and Ross (2006) promoted learners to look carefully at diagrams, pictures, titles, and subtitles to become familiar with the intention of the text and activate prior information about the topic; thus, before the learners start reading, previewing and predicting enable them to better comprehend the meaning of the text.

The while-reading stage helps learners to be active while they read and enables them to follow the text to understand the order of ideas and information it includes. In this stage, learners make notes by writing some useful information, ask questions, check prior knowledge, and make predictions about what is going to happen in the next part of the text. In the pre-reading stage, the teacher can encourage students to write some questions about the text and in the while-reading stage they attempt to find the answers to those questions (Hedge, 2008). Roe and Ross (2006) believed that identifying the main ideas of the text or book is, in fact, concerned with the findings of the significant information available in that text or book. Tompkins (2007) explained that by using this strategy, "children learn the difference between the big ideas and the details" (p. 205). 
In the post-reading stage, there are various activities, but using these activities in the class should be closely related to the reading purpose. Learners should use their notes and what they have read meaningfully. They can discuss the text, do role play, develop vocabulary, and answer the post-reading questions (Hedge, 2008). To check learners' understanding in this stage, learners start to work in small groups. Meanwhile, the teacher asks questions, gets information from the groups, and corrects students' mistakes. This collaborative classroom work helps learners become aware of their thinking process as they read the text. Group work, peer interaction, or collaborative classroom work are highly motivating factors. In this stage, the teacher acts as a person who organizes and guides when necessary (Hedge, 2008).

2.2 Self-efficacy

One of the most significant issues that Bandura's social cognitive theory focuses on is self-efficacy. The first roots of Bandura's theories were in the 1960s when he introduced his theory of social-behaviorism. His system had both characteristics of behaviorism and cognitive features. In 1977, with the publication of self-efficacy, he drew scholars' attention toward self-beliefs (Tilfarlioglu \& Cgnkara, 2009). For Bandura (1986), self-efficacy is the "judgment of [learners'] capabilities to recognize and execute courses of action to attain designated types of performances" (p. 391). Self-efficacy is not learners' skills. It is nothing, but the learners' attitude and idea about what their abilities in different situations are and how they behave when they encounter difficulties. According to Tilfarlioglu and Cgnkara (2009), self-efficacy mediates between knowledge and action. In learning situations, it puts emphasis on learners' beliefs and motivation. Therefore, the movement from having adequate knowledge to superior performance in a task is mediated by the learner's efficacious beliefs.

Schunk (2012) compared self-efficacy with outcome expectations and added that they do not have the same meaning. Self-efficacy refers to the ways that one thinks about his capabilities and abilities to create actions; in contrast, outcome expectations include the anticipation of the results of individuals' actions. For example, admiring a student when he replies to the teacher's questions appropriately can be considered as a positive outcome expectation. On the other hand, a low-efficacious student is not sure whether he can answer the questions correctly or not. In some cases, such a student does not even try to reply because of his uncertainty in his capabilities.

Baron (2004) categorized self-efficacy into the three types of social self-efficacy, self-regulatory self-efficacy, and academic self-efficacy. Social self-efficacy refers to one's ability to keep relationship, become involved in social activities, and become confident. Self-regulatory self-efficacy is thinking carefully and preventing hazardous activities while academic self-efficacy refers to the individual's ability to take part in activities and become involved in academic programs (Ghonsooly \& Elahi, 2010).

According to Bandura (1997), self-efficacy beliefs derive from four principal sources of information including mastery experiences, vicarious experiences, social persuasion, and physiological factors. Mastery experiences cover prior task accomplishments and it is not only the most powerful source but also a vital factor in establishing a sense of selfefficacy (Bandura, 1997). Schunk (2012) believed that "actual performances offer the most valid information for assessing efficacy" (p. 147). Teachers simplify mastery experience through practice and academic help such as thinking maps, modeling, feedback, and cognitive strategies (Bandura, 1977). Mastery experience promotes learners to be selfdirected and helps them to develop their ability to think intelligently (Zimmerman, 2006). Learners who give special attention to mastery experiences are more critical thinkers, strategic users, and resourceful learners (Pajares, 2006).

Schunk (2012) stated that learners increase their knowledge about their capabilities by watching others' performance. Consequently, another source of vicarious learning is observing other people by which the learner can develop his selfefficacy. Moreover, by observing peoples' successes with continual effort, learners raise their self-efficacy and begin to believe that they possess the same capabilities to be successful in doing the same task or activity. Social persuasion is another source for enhancing individuals' self-efficacy belief. Persuasion information and encouraging comments (e.g., "you can do it") by the teacher will promote learners' self-efficacy and motivation.

Decreasing individuals' self-efficacy can be done through social effect (Bandura, 1995). In this case, gaining positive effects inspire and give more control over learners' life, while negative ones overpower and reduce learners' selfefficacy (Pajares, 2006).

Bandura (1997) believed that peoples' capabilities depend on their physiological and emotional states. These states can vary from positive states like happiness and excitement to negative ones like stress, tension, and anxiety. This source of self-efficacy is one of the emotional states; therefore, it is very complex to measure.

\subsection{Enactive learning}

Richards and Schmidt (2002) stated that learning is "the process by which change in behavior, knowledge, skills, etc., comes about through practice, instruction, or experience and the result of such a process" (p. 298). Schunk (2012) suggested that individuals' learning occurs through enactive or vicarious learning. LaRose et al. (2012) believed that these two types of learning provide students with the knowledge they need for their future behavior. Enactive learning deals with one's learning from the results of his own learning actions. In fact, it is "learning through actual doing" (Schunk, 2012, p. 121). Enactive learning is not same as operant conditioning since operant conditioning strengthen or weaken the effects of individuals' behavior, but enactive learning refers to the consequences that lead individuals to gain information (Elia \& Poce, 2010). LaRose et al. (2012) explained that "people can also self-evaluate their behaviors through their own experience, that is, enactive learning" (p. 2582).

Bruner's (1966) ideas which are called "enactive, iconic, and symbolic learning" are somehow similar to that of Bandura's (cited in Ellis, 2001, p. 23). In Bruner's (1966) research, the focus is on enactive modes. The simple explanation of enactive learning, as mentioned above, is learning by doing, that is, by experiencing with the body 
(Brauer, 2002). Another study which is conducted by Rose (1999) revealed that enactive learning is effective and helpful with young children and for early reading development. According to Bruner (1966), experiential learning is another name for enactive learning in which learners engage in a particular act of learning and always intend to learn. As stated by Bruner (1966), in iconic learning, which is similar to vicarious learning, students make use of materials such as pictures, graphs, maps, film, video, CD-ROM's, drawing, and so on.

\subsection{Vicarious learning}

It is believed that to develop language and acquire knowledge about objects, children use the nonlinguistic processing of direct and vicarious experience. Hence, another distinctive human quality in the social cognitive theory is the advanced capability for vicarious learning (Bandura, 1989). That is, most of the time, learning takes place vicariously and without learners' performance (Schunk, 2012). Bandura (1989) stated that vicarious learning is "what people see and hear without direct experiential correctives" (p. 22). Schunk (2012) asserted that in vicarious learning, the popular sources of learning are "observing or listening to models who are live (appear in person), symbolic or non-human (e.g., televised talking animals, cartoon characters), electronic (e.g., television, computer, video-tape, DVD), or in print (e.g., books, magazines)" (p. 121). He added that vicarious learning prevents people from experiencing negative results.

According to Campbell (2010), there are advantages and opportunities that learners get from vicarious learning. While learners use their own ideas and beliefs independently from others, they will understand their teacher, friends, and others and receive their instant feedback. Moreover, there will be cooperative learning in groups because of peer models. Roberts (2010) expressed that learning vicariously is "learning from others' experience through discussion (or discourse), conflict, challenge, support, and scaffolding from a more competent other and storytelling" (p. 13). He believed that by using the term "other people" scholars do not only mean teachers, but also "peers who are other people in a similar situation" (p. 14). In vicarious learning, there is no need for a real performance of learners. Learners like to observe models that demonstrate and show beneficial actions. Vicarious learning enables individuals to learn complicated skills by observing teaching models. Individuals enjoy learning skills through observation, practice, and teachers' feedback. In vicarious learning, the learner can show actions after observing the modeled behavior (Ryan, 2012).

\section{Methodology}

\subsection{Participants}

This study was conducted on nonnative students studying English at language institutes in Iran. Participants comprised of seventy female EFL learners of pre-intermediate level studying English at two institutes, located in Hashtgerd. The participants were divided into two groups of thirty five students of which one was being taught enactively while the other was taught vicariously.

The participants' age ranged from 10 to 25. Most of them were high school students. Four students who were absent for several teaching sessions were omitted from the study. The data coming from two other students who were absent in post-test session were also eliminated.

\subsection{Instruments}

To reach the purpose of the study, several instruments were employed. These include proficiency test, reading and selfefficacy pre-tests, and the post-tests of reading and self-efficacy.

Two pre-tests for collecting the data required in achieving the research objectives were employed. A pre-test of reading comprehension was given to all learners to check their reading comprehension ability. The pre-test which was a reading passage contained twenty comprehension questions. This passage was selected from American English File at the starter level by Oxenden and Latham-Koenig (2010). The other pre-test was a self-efficacy questionnaire. The selfefficacy questionnaire consisted of thirty items with 5-point Likert-Scale response options developed by Sherer et al. (1982). Hamill (2002) believed that "this measure was designed to assess general expectations of self-efficacy that are not tied to specific situation or behavior" (p.120). Participants read the statements in the questionnaire and according to their efficacious beliefs, they chose one of the options ranged from 1 to 5 corresponding to strongly disagree, somewhat disagree, neither agree nor disagree, somewhat agree and strongly agree respectively.

At the end of the treatment period both groups received a post-test of reading comprehension and a self-efficacy questionnaire. The former was a reading test made up of a reading passage with twenty comprehension questions. This passage was selected from the American English File at the starter level (Oxenden \& Latham-Koenig, 2010). The latter was the same self-efficacy questionnaire which was formerly used as a pre-test and students, themselves, rated as it was described above.

\subsection{Procedure}

In this study, in order to test the hypotheses, several steps were taken including selection of the subject, pre-tests of reading comprehension and self-efficacy, choosing reading passages, teaching enactively or vicariously and post-tests of reading comprehension and self-efficacy. The process of receiving the treatments took eighteen sessions and the learners had the opportunity to learn enactively or vicariously three times each week. In order to homogenize the students in terms of their language proficiency and have pre-intermediate subjects, a placement test was administered by the institutes. On the first session and before exposing students to different methods of teaching and enabling them to receive the related treatments, to gather some quantitative information about the learners' performance, the subjects in both groups received pre-tests of reading comprehension and completed the learners' self-efficacy scale. Twelve reading passages were selected from Elementary Steps to Understanding by Hill (2001). Every session, the teacher gave 
the copies of the passages to the subjects to work on enactively or vicariously. During the treatment phase in the first group, reading were taught enactively through actual pre-reading tasks. Teaching enactively, the teacher encouraged learners to choose the title based on the pictures, write about the pictures, talk about the topic, read the text and underline the unfamiliar words, use dictionaries to determine the meaning of unfamiliar words, write about what will happen next, do the pre-reading tasks individually, write a summary about what they have read, etc.

In the second group, on the other hand, during the pre-reading phase, subjects were provided with the necessary information vicariously. Such being the case, the learners observed and listened to models. The teacher taught students by modeling, using electronic devices such as television, computers, DVD players, books, magazines, and printed papers. The teacher showed the students the picture of the reading text and after that she wrote three or four titles for the picture of the text. Then, she wrote the unfamiliar words on the board and explained the meaning of unfamiliar words and wrote them on the board. Televisions, computers, and DVD players were employed two or three times for working on the text.

In the last session (i.e., the 18th session), to obtain quantitative information on the subjects' progress, two post-tests were administered to each group - one for reading comprehension and the other for self-efficacy. The results obtained from the pretests and the post-tests were then employed to check the hypotheses.

\subsection{Design}

Today in methodological research and in data collection, there is a wide range of methods, design, and techniques. The study was conducted through a quasi-experimental, pre-test, post-test, nonequivalent groups design. As Best and Kahn (2006) suggested, this design is normally used when there are classroom experiments. The subjects were divided into two groups that received enactive and vicarious training. First in both groups the proficiency test, the pre-test of reading, and the questionnaire of self-efficacy were administered. Then, one group received enactive treatment, while the other was treated vicariously. Finally, the post-test of reading and the questionnaire of self-efficacy were administered. Enactive learning and vicarious learning were independent variables and the dependent variables were self-efficacy and reading comprehension.

\section{Results and Discussion}

The data, in this research, was collected in order to investigate the impact of enactive and vicarious learning on participants' reading comprehension and self-efficacy.

The first hypothesis raised in this study was that "enactive pre-reading tasks do not affect Iranian pre-intermediate EFL learners' reading comprehension". This hypothesis was designed to determine if the effects of enactive experiences could be increased when used in reading comprehension. After administrating the pre-test of reading, participant were taught enactively to observe if there is any improvement in the learners' reading comprehension. At the end of the term, the researchers evaluated the learners' reading comprehension by post-test. By observing t-value ( -3.79$)$ and significance level $(.001<.01)$ in Table 1 , it is concluded that there is a statistical difference between the subjects' performance in the reading pre-test and post-test; therefore, the first null hypothesis is rejected. In other words, enactive learning is effective in reading comprehension and the students' reading comprehension improved considerably by using enactive learning.

Table 1. Paired samples test of pre-test and post-test of reading comprehension in the enactive group

\begin{tabular}{|c|c|c|c|c|c|c|c|c|}
\hline & \multicolumn{5}{|c|}{ Paired Differences } & \multirow[t]{3}{*}{$\mathrm{t}$} & \multirow[t]{3}{*}{ df } & \multirow{3}{*}{$\begin{array}{l}\text { Sig. }(2- \\
\text { tailed) }\end{array}$} \\
\hline & \multirow[t]{2}{*}{ Mean } & \multirow[t]{2}{*}{$\begin{array}{c}\text { Std. } \\
\text { Deviation }\end{array}$} & \multirow[t]{2}{*}{$\begin{array}{l}\text { Std. } \\
\text { Error } \\
\text { Mean }\end{array}$} & \multicolumn{2}{|c|}{$\begin{array}{l}95 \% \text { Confidence } \\
\text { Interval of the } \\
\text { Difference }\end{array}$} & & & \\
\hline & & & & Lower & Upper & & & \\
\hline $\begin{array}{ll}\text { Pair } 1 & \text { pre.enactive.reading - } \\
\text { average.post.enactive.reading }\end{array}$ & -1.81373 & 2.78381 & .47742 & -2.78504 & -.84241 & -3.799 & 33 & .001 \\
\hline
\end{tabular}

The second hypothesis stated that "vicarious pre-reading tasks do not affect Iranian pre-intermediate EFL learners' reading comprehension". In order to verify this hypothesis, after the pre-test of reading, participants were taught vicariously. At the end of the term, the researchers measured the learners' reading comprehension through a post-test. In order to determine whether the vicarious pre-reading tasks were affective and the difference between results obtained in the pre-test and post-test of reading in the vicariously taught group is significant, a paired samples t-test was employed. As Table 2 showed, the t-value is .230 and the significance level is .819 that is far beyond the standard .05 levels. Thus, it is concluded that there is no significant difference between the pre-test and post-test results and accordingly the second null hypothesis is not rejected. 


\begin{tabular}{|c|c|c|c|c|c|c|c|}
\hline & \multicolumn{5}{|c|}{ Paired Differences } & \multirow[t]{3}{*}{$\mathrm{t} d f$} & \multirow{3}{*}{$\begin{array}{l}\text { Sig. }(2- \\
\text { tailed) }\end{array}$} \\
\hline & \multirow[t]{2}{*}{ Mean } & \multirow[t]{2}{*}{$\begin{array}{c}\text { Std. } \\
\text { Deviation }\end{array}$} & \multirow[t]{2}{*}{$\begin{array}{l}\text { Std. } \\
\text { Error } \\
\text { Mean }\end{array}$} & \multicolumn{2}{|c|}{$\begin{array}{l}95 \% \text { Confidence } \\
\text { Interval of the } \\
\text { Difference }\end{array}$} & & \\
\hline & & & & Lower & Upper & & \\
\hline $\begin{array}{ll}\text { Pair } & \text { pre.vicarious.reading - } \\
1 & \text { average.post.vicarious.reading }\end{array}$ & .14323 & 3.51534 & .62143 & -1.12419 & 1.41065 & .23031 & .819 \\
\hline
\end{tabular}

The third hypothesis of the study was that "enactive pre-reading tasks do not affect Iranian pre-intermediate EFL learners' self-efficacy". Thirty four learners from the enactive group completed the pre-test of self-efficacy questionnaire. After being exposed to enactive methods of learning, the learners received a questionnaire of selfefficacy. Employing the Mann-Whitney U test, the data was analyzed for statistically significant variations using SPSS. Table 3 indicated the ranks of the participants' self-efficacy in the enactive group. By observing mean ranks, it can be concluded that there is a difference between the learners' performance before and after the treatment in the enactive group; however, since the mean rank cannot indispensably show the significance of the difference, the researchers referred to the asymptotic significance $(0.280)$ in Table 4 that showed this difference between the mean ranks is not significant. Thus, the third hypothesis is not rejected.

Table 3. Ranks of participants' self-efficacy

\begin{tabular}{llrrr}
\hline & pretest.posttest & N & Mean Rank & Sum of Ranks \\
\hline \multirow{3}{*}{ selfefficacy.enactive.pre.post } & pretest & 34 & 31.91 & 1085.00 \\
& posttest & 34 & 37.09 & 1261.00 \\
& Total & 68 & & \\
\hline
\end{tabular}

Table 4. Comparing of self-efficacy before and after receiving the treatment in the enactive group

\begin{tabular}{lr}
\hline & selfefficacy.enactive.pre.post \\
\hline Mann-Whitney U & 490.000 \\
Wilcoxon W & 1085.000 \\
Z & -1.081 \\
Asymp. Sig. (2-tailed) & .280 \\
\hline
\end{tabular}

a. Grouping Variable: pretest.posttest

The last hypothesis raised in this study is that "vicarious pre-reading tasks do not affect Iranian pre-intermediate EFL learners' self-efficacy". Thirty two learners from the vicarious group completed the self-efficacy questionnaire before the treatment. After receiving the materials vicariously, the learners completed the self-efficacy questionnaire. Table 5 indicated that the mean rank of self-efficacy after receiving the treatment is higher than before receiving any treatment and Table 6 illustrated that there is also a significant difference between the learners' self-efficacy before and after the treatment in the vicarious group ( $\mathrm{p}$-value $<0.05$ ). Accordingly, the last null hypothesis was rejected. Hence, it is concluded that the vicarious lessons positively impacted on students' self-efficacy.

Table 5. Ranks of participants' self-efficacy

\begin{tabular}{llrrr}
\hline & pretest.posttest & N & Mean Rank & Sum of Ranks \\
\hline & pretest & 32 & 25.77 & 824.50 \\
selfefficacy.vicarious.pre.post & posttest & 32 & 39.23 & 1255.50 \\
& Total & 64 & & \\
\hline
\end{tabular}

Table 6. Comparing of self-efficacy before and after receiving the treatment in the vicarious group

\begin{tabular}{lr}
\hline & selfefficacy.vicarious.pre.post \\
\hline Mann-Whitney U & 296.500 \\
Wilcoxon W & 824.500 \\
Z & -2.897 \\
Asymp. Sig. (2-tailed) & .004 \\
\hline
\end{tabular}

a. Grouping Variable: pretest.posttest 


\section{Conclusion}

Pajares (2002) expressed that by using social cognitive theory as a framework, teachers can improve learners' personal characteristics including emotional states, self-beliefs, and habits of thinking. They will also improve learners' behaviors such as academic skills and self-regulatory practices. Students' success which is a kind of environmental factor is also improved using social cognitive theory. In general, the purpose of the study was to portray the framework of social cognitive theory (Bandura, 1986), and in particular, it aimed to investigate the impact of enactive and vicarious pre-reading tasks on Iranian pre-intermediate EFL learners' reading comprehension and self-efficacy. Providing the participants with various opportunities to learn enactively or vicariously via observation, the researchers attempted to investigate the related hypotheses. The results of the study presented a rich opportunity to explore the social cognitive theory beyond traditional methods. In brief, the results employed in verification of the four hypotheses presented above indicated that the participants who learn enactively have more improvement in their reading comprehension than those who learn vicariously. Vicarious learning in comparison with enactive learning seemed more productive in helping the participants to improve their self-efficacy.

It was observed that the enactive learning helped learners to overcome the issue of not having a teacher. The findings suggested that learners, by their own doing, can conquer the obstacles they encounter in their reading comprehension without necessarily needing a teacher. This might be explained in terms of the fact that learning enactively and independently puts more responsibility on learners' shoulders and this increases the efforts they make in any reading comprehension process. In this respect Moon (2013) explained that when learners are involved in actions, they are more responsible for their learning.

Vicarious learning involves the teacher as a model who explains and acts as a model. The learners have the opportunity not only to share their thoughts with the other groups but also to receive feedback immediately from their teachers and peers. In observational learning, the teachers and learners act as models through which learners observe the others' performance. As the study indicated, vicarious learning influences individuals' self-efficacy. Encouraging learners just to observe the model and taking their responsibility away from actively engaging in pre-reading tasks creates a less stressful environment. The absence of anxiety in language classes might increase students' self-efficacy. What the researchers found based on which it is claimed that individuals' self-efficacy can be raised by observing is in line with what Schunk (2008) stated.

During classroom instruction, EFL teachers may use diverse reading tasks, techniques, and strategies. One example is the use of a picture walk as a pre-reading task. According to Iwai (2011), picture walk enables learners to gain an understanding of what a story or text is about by looking at pictures before reading the text. In this study, the teacher played different roles at different groups. In enactive classes the teacher, first, asked learners to write some titles for the reading text by looking at the pictures. Then, she used the picture walk and told learners to write about the pictures. After that students underlined the new words and looked them up in dictionaries on their own. Since one of the learners' main difficulties is the vocabulary taught in the text (Pardo, 2004), finding and learning the meaning of these vocabularies help them to identify the purpose of the written text. Finally, before reading, the participants had to underline verbs, nouns, and adjectives. These pre-reading tasks which were conducted by learners seem to lead to the improvement of their reading comprehension.

In the vicarious group, the role of the teacher as a planner, manager, or model of the programs was extremely difficult. It is the model or the teacher who had to talk about the title of the text and explain the picture and write the explanation on the board. The model expanded the ideas by adding further questions and activating learners' background knowledge by explaining the titles and pictures, using the movie player, writing new words with their meanings on the board, using semantic mapping before reading the text, and adding some information after reading if it was necessary. Semantic mapping is "a graphic display of a cluster of words that are meaningfully related" (Iwai, 2011, p. 156). Observing these pre-reading tasks such as models, videos, etc. enabled students to become self-efficacious learners. According to Ghonsooly and Elahi (2010), the most affective factors influencing language learning are self-efficacy and anxiety. One possible explanation for this effect might be the fear or anxiety that students experience while doing tasks by themselves. In addition, the feeling of doing tasks in a wrong way may have not let the enactive group to increase their general self-efficacy significantly. Thus, anxiety may affect their self-efficacy. Ghonsooly and Elahi (2010) stated that "high self-efficacious participants experienced lower anxiety than low self-efficacious participants" (p. 57).

Based on the findings of the study, there are some suggestions that may be beneficial for teachers. First, in order to achieve specific goals, it may be helpful for teachers to employ appropriate tasks, strategies, and a variety of methods. Second, before any teaching, it might be advantageous for teachers to teach the pre-reading tasks and strategies by using instruments or modeling so that learners may become familiar with the text before reading. Next, most learners are able to learn independently and by their own doing without any help and support from their teachers. Therefore, it is concluded that teaching vicariously is not very effective in reading comprehension classes. This might be due to the fact that in the vicarious group, students did not feel responsible enough to carry the loads of learning on their own shoulders. As Kang (2005) stated, when individuals are more responsible, they are more willing to communicate. This willingness to communicate plays an important role in learning a second or foreign language. The lack of such a factor may lead individuals to consider the model as the main source of information for learning. Finally, it may be of great assistance for EFL teachers to mix and integrate enactive and vicarious teaching by providing diverse instruments and pre-reading tasks to facilitate the individuals to become independent and self-efficacious learners. 
From a pedagogical point of view, enactive and vicarious learning strategies are an effective tool both for EFL teachers and learners. In cases where most of the learners deal with teacher-centered learning, enactive learning may help them to become independent readers in their target language.

\section{References}

Bandura, A. (1969). Principles of behavior modification. New York: Holt, Rinehart and Winston.

Bandura, A. (1977). Social learning theory. Englewood Cliffs, NJ: Prentice-Hall.

Bandura, A. (1986). Social foundations of thought and action: A social cognitive theory. Englewood Cliffs, NJ: Prentice-Hall.

Bandura, A. (1989). Human agency in social cognitive theory. The American Psychological Association, 44(9), 11751184.

Bandura, A. (1995). Self-efficacy in changing societies. New York: Cambridge University Press.

Bandura, A. (1997). Exercise of personal and collective efficacy in changing societies. In A. Bandura (Ed.), Selfefficacy in changing societies. London: Cambridge University Press.

Baron, A. R. (2004). Social psychology (10 th ed.). Boston: Allyn \& Bacon.

Best, J. \& Kahn, J. (2006). Research in education. Boston: Allyn \& Bacon.

Brauer, M. (2002). Social power and group perception: Discussion and integration. Paper presented at the General Meeting of the European Association of Experimental Social Psychology, San Sebastian, June 2002.

Bruner, J. (1966). Toward a theory of instruction. Cambridge, MA: Harvard University Press.

Campbell, J. (2010). Social cognitive theory. Retrieved from

http://uhaweb.hartford.edu/JCAMPBELL/JCampbell/Courses_files/Social\%20Cognitive\%20Learning.pdf

Chastain, K. (1988). Developing second-language skills: Theory and practice ( ${ }^{\text {rd }}$ ed.). San Diego: Harcourt Brace Jovanovich.

Elia, G., \& Poce, A. (2010). Open networked i-learning: Models and Cases for "Next-Gen” Learning. New York: Springer.

Ellis, A. (2001). Overcoming destructive beliefs, feelings, and behaviors: New directions for Rational Emotive Behavior Therapy. Amherst, NY: Prometheus Books.

Ghaemi, F., \& Mirhassani, A. (2007). Language teaching theories, approaches, methods, and skills. Tehran: Kasa Kavosh.

Ghonsooly, B., \& Elahi, M. (2010). Learners' self-efficacy in reading and its relation to foreign language reading anxiety and reading achievement. The Journal of English Language Teaching and Learning, 53(217), 45-67.

Hamill, S. K. (2002). Resilience and self-efficacy: The importance of efficacy beliefs and coping mechanism in resilient adolescents. Retrieved from http://groups.colgate.edu/cjs/student_papers/2003/Hamill.pdf.

Hedge, T. (2008). Teaching and Learning in the Language Classroom. Oxford: Oxford University Press

Hill, L. A. (2001). Steps to understanding. Oxford University Press: Oxford.

Iwai, Y. (2011). The effects of metacognitive reading strategies: Pedagogical implications for EFL/ESL teachers. The Reading Matrix, 11(2), 150-159.

Kang, S. J. (2005). Dynamic emergence of situational willingness to communicate in a second language. System, 33, 277-292.

LaRose, R., DeMaagd, K., Chew, H. E., Sandy Tsai, H, Y., Steinfield, C., Wildman, S. S., \& Bauer, J. M. (2012). Measuring sustainable broadband adoption: An innovative approach to understanding broadband adoption and use. International Journal of Communication, 6 ,2576-2600.

Moon, J. A. (2013). A handbook of reflective and experiential learning: Theory and practice. New York: Routledge.

Oxenden, C., \& Latham-koenig, C. (2010). American English file starter. Oxford University Press: Oxford.

Pajares, F. (2006). Self-efficacy during childhood and adolescence: Implications for teachers and partners. In F. Pajares \& T. Urden (Eds.), Self-efficacious beliefs of adolescents (pp.339-367). Greenwich, CT: Information Age Publishing.

Pardo, L. S. (2004). What every teacher needs to know about comprehension. The Reading Teacher, 58, 272-280.

Pressley, M., \& Hilden, K. (2002). How can children be taught to comprehend text better? In M.L. Kamil, J.B. Manning, \& H.J. Walberg (Eds.), Successful reading instruction: Research in educational productivity (pp. 33-51). Greenwich, CT: Information Age Publishing.

Richard, C. R.,\& Schmidt, R. (2002). Longman dictionary of language teaching and applied linguistic (3 ${ }^{\text {rd }}$ ed.). London: Pearson.

Roberts, D. (2010). Nurse education in practice. Elsevier Journal, 10(2010), 13-16. 
Roe, B.D., \& Ross, E.P. (2006). Integrating language arts through literature and thematic units. Boston: Pearson Education.

Rose, D. (1999). The impact of Whirlwind's Basic Reading Through Dance program on first grade students' basic reading skills: Study II. San Francisco: 3-D Group.

Ryan, R. M. (2012). The oxford handbook of human motivation. Oxford: Oxford University Press.

Schunk, D. H. (2008). Attributions as motivators of self-regulated learning. In D. H. Schunk \& B. J. Zimmerman (Eds.), Motivation and self-regulated learning: Theory, research, and applications (pp. 245-266). New York: Taylor \& Francis.

Schunk, D. H. (2012). Learning theories: An educational perspective ( $6^{\text {th }}$ ed.). The University of North Carolina at Greensboro: Pearson Education.

Sherer, M., Maddox, J. E., Mercandante, B., Prentice-Dunn, S., Jacobs, B., \& Rogers, R.W. (1982). The self-efficacy scale: Construction and validation. Psychological Reports, 51, 663-671.

Stanley, S. F. (1978). Family education to enhance the moral atmosphere of the family and the moral development of adolescents. Journal of Counseling Psychology, 25(2), 110-118.

Talçın Tilfarlioglu, F., \& Cgnkara, E. (2009). Self-efficacy in EFL: Differences among proficiency groups and relationship with success. Novitas-Royal, 3(2), 129-142.

Tompkins, G. E. (2007). Literacy for the 21st century: Teaching reading and writing in prekindergarten through grade 4 ( $2^{\text {nd }}$ ed.). Upper Saddle River: Pearson Education.

Wong, M. S. L. (2005). Language learning strategies and language self-efficacy: Investigating the relationship in Malaysia. RELC journal, 36(3), 245-269.

Zainol Abidin, M. J., \& Riswanto, R. (2012). Collaborative strategic reading (CSR) within cognitive and metacognitive strategies perspectives. International Journal of Humanities and Social Science, 2(3), 61-70.

Zimmerman, J. (2006). Why some teachers resist change and what principals can do about it. NASSP Bulletin, 90(3), 238-249. 